\title{
O PAPEL DO COMPUTADOR EM ATIVIDADES DIDÁTICAS: UM OLHAR PARA O ENSINO DE FÍSICA
}

\author{
Dioni Paulo Pastorio, UFSM, dionipastorio@ hotmail.com \\ Ricardo Andreas Sauerwein, UFSM, rsauer.ufsm@gmail.com
}

\begin{abstract}
Resumo: Neste trabalho desenvolvemos uma pesquisa bibliográfica em dois periódicos nacionais (Revista Brasileira de Ensino de Física e Caderno Brasileiro de Ensino de Física), relacionados ao ensino de Física. Nesta pesquisa, procuramos evidenciar qual o papel empregado ao computador nos artigos selecionados. E ainda mapear os conteúdos conceituais relacionados à disciplina de Física, desenvolvidos nas atividades descritas nos periódicos. Os resultados apontam para um uso considerável de simulações computacionais, aparecendo com maior ênfase inclusive quando comparada a atividades experimentais, importante atividade didática nas aulas de Física. Destacam-se também, a parcela relacionada aos artigos que desenvolvem teorias de aprendizagem a partir do computador. Ainda, por fim, com relação aos conteúdos abordados, destacam-se Cinemática e também o de Física Moderna.
\end{abstract}

Palavras-Chave: simulações computacionais, ensino de física, computador, atividades experimentais.

\section{COMPUTER PAPER IN TEACHING ACTIVITIES: A LOOK FOR PHYSICAL EDUCATION}

Abstract: In this work a literature search in two national journals (Revista Brasileira de Ensino de Física e Caderno Brasileiro de Ensino de Física), related to physics teaching. In this research seeks to show what role the employee computer on selected articles. And map the conceptual contents related to the discipline of physics, developed in the activities described in journals. The results point to a considerable use of computer simulations, appearing with greater emphasis even when compared to experimental activities, important didactic activity in Physical. Noteworthy are also the installment related to articles that develop learning theories from the computer. Yet, finally, with respect to the content addressed, stand out kinematics and also the Modern Physics.

Keywords: computer simulations, physical education, computer, experimental activities.

\section{INTRODUÇÃO}

As práticas didáticas adotadas pelos professores de Física em sala de aula têm se baseado atualmente, em geral, em uma aula fundamentada extensivamente na exposição de conteúdos pelo professor, no uso do quadro negro e giz, e ainda aliada a uma alta taxa de resolução de exercícios. Esta prática didática é conhecida como "método tradicional". Conforme Heineck (2007, p.1), "Relativo ao ensino de Física, atualmente o modelo adotado por alguns educadores tende a obedecer ao método tradicional de simples repasse de conteúdos, com aulas à base de giz, quadro-verde e livro didático". 
Porém a sala de aula está exposta à evolução tecnológica observada na sociedade em geral. Os meios de comunicação, os veículos, a medicina, tudo evolui rapidamente, e a escola também deve acompanhar esta evolução.

Neste sentido, as Tecnologias de Informação e Comunicação (TIC), hoje, acessíveis à grande maioria da população ${ }^{1}$, oferecem um acesso à informação diário e atualizado, o que pode mudar a forma com que o aluno estuda e aprende. Conforme (Brasil, 2002, p.88), “é inegável que a escola precisa acompanhar a evolução tecnológica e tirar o máximo de proveito dos benefícios que esta é capaz de proporcionar".

Além disso, os $\mathrm{PCN}^{2}{ }^{2}$ (BRASIL, 2002) conferem importância fundamental às tecnologias, relacionando com o caráter social da aprendizagem ao destacar que:

\begin{abstract}
A escola não pode ficar alheia ao universo informatizado se quiser, de fato, integrar o estudante ao mundo que o circunda, permitindo que ele seja um indivíduo autônomo, dotado de competências flexíveis e apto a enfrentar as rápidas mudanças que a tecnologia vem impondo à contemporaneidade (BRASIL, 2002, p. 229-230).
\end{abstract}

Já em relação ao computador, Araújo e Veit (2004, p.5) ressaltam que "os computadores estão onipresentes na maior parte das áreas do conhecimento humano, desde a construção de usinas atômicas à elaboração de uma simples planilha para o controle do orçamento doméstico".

Assim sendo, acredita-se que, se essas tecnologias forem incorporadas nas nossas escolas atuais, podem proporcionar um ambiente de aprendizado que condiz com a sociedade na qual o aluno está inserido. Os estudantes que hoje adentram às salas têm acesso a muitas ferramentas que podem ser úteis ao professor em sua aula. Os avanços tecnológicos devem ser incorporados, pois o professor tem em mãos uma quantidade de novos recursos ao seu dispor, como variedade de textos, figuras, animações, sons, jogos, aplicativos interativos, simulações computacionais, que podem tornar a aula mais dinâmica e interativa, proporcionando um processo de ensino-aprendizagem em que o estudante sinta-se mais envolvido.

Contudo, o simples fornecimento destes materiais, como os computadores e tablets, mesmo para uso didático, não garante sucesso no processo de ensinoaprendizagem. É função do professor planejar as aulas de acordo com as necessidades impostas por estas estratégias, para que o objetivo de ensinar seja realmente alcançado. Como destacam Macedo, Dickman e Andrade (2004), a necessidade de o professor estar preparado para atividades inovadoras como esta é fundamental. Isso indica que de nada adianta introduzir materiais de tecnologia avançada na sala de aula, se o docente não está devidamente preparado para trabalhar com estes equipamentos.

Segundo Fiolhais e Trindade (2003), foi no início do presente século, com o aparecimento da internet e o desenvolvimento de notebooks, que o uso dos computadores no ensino de crianças e adolescentes ficou mais intenso.

Se o uso de computadores em atividades didáticas é algo já consolidado desde os anos 2000, conforme Fiolhais e Trindade (2003) restam alguns questionamentos acerca do tema: a) para que tipo de atividade o computador é utilizado como ferramenta didática em sala de aula? b) atividades de coleta de dados ainda são a principal função

\footnotetext{
${ }^{1}$ Através da televisão, rádio, jornais e internet, por exemplo.

${ }^{2}$ Orientações Educacionais Complementares aos Parâmetros Curriculares Nacionais (PCN).
} 
dos computadores nas salas de aulas? ${ }^{3}$

c) as simulações computacionais já são atividades consolidadas nas salas de aula?

$\mathrm{Na}$ tentativa de responder estes questionamentos e de identificar as diversas correntes relativas ao uso do computador em sala de aula, optou-se por realizar uma revisão bibliográfica em artigos científicos nacionais que estão voltados diretamente à prática docente de Física, tanto no ensino médio quanto no ensino superior. Ainda, definiu-se também como objetivo desta revisão criar um mapeamento conceitual sobre essas publicações. Ou seja, foram classificados e analisados os artigos na busca de identificar quais são os conceitos Físicos envolvidos nas atividades, destacando os que recebem maior e menor atenção.

Para desenvolver esta revisão, procurou-se analisar as publicações que se iniciaram no ano 2000 e perduraram até o ano de 2011, tendo em vista o uso de computadores no ensino de Física. A investigação foi realizada sobre duas revistas científicas de circulação nacional, o Caderno Brasileiro de Ensino de Física $(\mathrm{CBEF})^{4}$ e a Revista Brasileira de Ensino de Física (RBEF) ${ }^{5}$.

A justificativa perante a escolha das revistas deu-se em torno do foco apresentado pelas mesmas. A RBEF visa a contribuir para a educação científica da sociedade como um todo, publicando artigos sobre aspectos teóricos e experimentais de Física, materiais e métodos instrucionais, desenvolvimento de currículo, pesquisa em ensino, história e filosofia da Física, política educacional e outros temas pertinentes e de interesse da comunidade engajada no ensino e pesquisa em Física.

Já o CBEF é voltado prioritariamente para os cursos de formação de professores de Física. Também é utilizado em pós-graduações em Ensino de Ciências/Física e em cursos de aperfeiçoamento para professores do Nível Médio. O mesmo tem por objetivo promover uma disseminação efetiva e permanente de experiências entre docentes e pesquisadores, visando a elevar a qualidade do ensino de Física tanto nas instituições formadoras de novos professores quanto nas escolas em que esses docentes irão atuar.

Desta forma, a partir destes focos, fica clara a ligação existente entre os periódicos escolhidos e as metodologias empregadas para o ensino de Física, o que é passível de análise neste texto.

\section{O ESTUDO REALIZADO}

Para a análise dos artigos, inicialmente, optou-se por um processo de filtragem. Esta seleção consistiu na leitura do título, do resumo e das palavras-chave de cada artigo, a fim de identificar aqueles que abordavam o uso do computador em atividades didáticas no ensino de Física. Caso fosse encontrada alguma informação que levasse a situação acima descrita, o artigo era selecionado para análise e interpretação; caso contrário, ele era automaticamente descartado.

Após este processo, deu-se a leitura completa dos artigos selecionados para, através da Análise Textual Discursiva (ATD) (MORAES; GALIAZZI, 2006), classificá-los em função de dois aspectos: a) se estão voltados à sala de aula; b) quanto aos conteúdos mais abordados na proposta descrita. Os resultados encontrados estão mostrados na próxima seção deste capítulo e estão divididos a partir da respectiva revista.

\footnotetext{
3 Admite-se que o computador era usado primordialmente em atividades experimentais, para uso em coleta automática e análise de dados.

${ }^{4}$ Esta revista possui avaliação no sistema Qualis Capes (2015) B1 para a área de Ensino.

${ }^{5}$ Este caderno possui avaliação no sistema Qualis Capes (2015) A1 para a área de ensino.
} 


\section{ANÁLISE DOS DADOS COLETADOS}

\section{Caderno Brasileiro de Ensino de Física}

Da investigação realizada nas últimas treze edições do CBEF (345 artigos publicados), foram selecionados 24 artigos que faziam menção ao uso do computador como ferramenta didática. A tabela 1 apresenta o número de artigos publicados em cada ano, além da porcentagem de artigos selecionados em relação ao número total.

Tabela 1 - Número de artigos publicados em cada ano no CBEF

\begin{tabular}{c|c|c|c}
\hline Ano & N de artigos & $\begin{array}{c}\text { Artigos } \\
\text { Selecionados }\end{array}$ & Porcentagem \\
\hline 2000 & 26 & 4 & 15,3 \\
\hline 2001 & 26 & 3 & 11,5 \\
\hline 2002 & 31 & 0 & 0 \\
\hline 2003 & 18 & 1 & 5,5 \\
\hline 2004 & 66 & 2 & 3,0 \\
\hline 2005 & 20 & 2 & 10,0 \\
\hline 2006 & 19 & 1 & 5,2 \\
\hline 2007 & 20 & 0 & 0 \\
\hline 2008 & 26 & 3 & 6,4 \\
\hline 2009 & 31 & 2 & 6,9 \\
\hline 2010 & 33 & 4 & 2,1 \\
\hline 2011 & 29 & 24 & 6,5 \\
\hline Total & 345 & & \\
\hline
\end{tabular}

Ao analisar-se a Tabela 1, observa-se uma quantidade pequena de artigos publicados relacionados ao uso do computador. É considerável ressaltar que, por dois anos (2002 e 2007), não foi encontrado nenhum texto de interesse na análise realizada. Como o campo de publicações do periódico é bastante amplo (vide foco descrito no início do capítulo), acredita-se que haja um equilíbrio nos temas publicados. Outro aspecto considerável é que existe certa linearidade no número de publicações relacionadas ao tema de interesse, uma vez que este número sempre foi semelhante ao longo das edições.

\section{Voltados à sala de aula}

Inicialmente, o foco da análise dos artigos, como já destacado, foi quanto à natureza de sua publicação; neste caso, se é voltado à sala de aula. Nesta etapa, restaram 18 artigos para reflexão. De acordo com a análise destas publicações, emergiram quatro categorias: 
- Simulações Computacionais: metade dos trabalhos voltados à sala de aula está relacionada ao uso de simulações computacionais. Através da análise realizada, encontraram-se relatos de atividades voltadas aos três níveis de ensino (médio, superior e tecnológico), o que pode apontar para a utilização gradativa destas estratégias em sala, embora apenas este indício não permita fazer alguma generalização.

Um trecho de um dos artigos selecionados evidencia a criação desta categoria.

Este estudo apresenta uma breve e panorâmica visão crítica sobre o uso das Tecnologias da Informação e Comunicação na Educação e, em especial, na Educação em Ciências, buscando, mais precisamente, centrar nossa atenção nos recursos da informática, com ênfase no uso e na adequação dos programas de simulação no ensino da Física. (SANTOS, 2008, p. 570)

- Atividade Experimental: outra grande parcela (porém, em menor quantidade do que a categoria anterior) dos artigos publicados é destinada ao uso do computador para fins experimentais. Dentre as características de seu uso, principalmente, valem-se de atividades de coleta de dados, ou, então, de análise gráfica. O fragmento abaixo explicita esta categoria.

Este artigo procura enfatizar a importância da experimentação na compreensão de um fenômeno físico sobre interferência, denominado batimento de ondas sonoras. Algumas alternativas para a realização do experimento são apresentadas e as limitações de cada uma delas são apontadas. $\mathrm{O}$ artigo apresenta, também, um software desenvolvido especificamente para este experimento, denominado Batimento... (SILVA et al, 2004, p.103)

- Aprendizagem: esta categoria relaciona estudos de teorias de aprendizagem e suas relações com o uso de computadores. De certa forma, caracterizam-se estes artigos como os que não foram aplicados em sala de aula e apresentam informações a respeito do uso do computador a partir de uma teoria de aprendizagem ou ainda dos processos de cognição envolvidos durante as atividades didáticas com TIC. Um exemplo de trecho de um artigo que possibilitou a identificação desta categoria foi "En este trabajo se discuten las ventajas y desventajas didacticas del uso de software de simulación en Física. Se establecen relaciones con la Teoria del Aprendizaje Signicativo de Ausubel." (SANTOS; OTERO; FANARO, 2000, p. 50).

- Formação de Professores: responsável pela categoria com o menor número de publicações, esta representa o uso acoplado de TIC com atividades de formação de professores. Esta ferramenta, neste contexto, apresentou-se como ferramenta motivacional para o estudo de determinado conteúdo, para a parcela de docentes envolvidos na pesquisa. $O$ extrato a seguir representa uma fala característica da respectiva categoria

O foco do artigo é a descrição da nova versão da unidade conceitual (voltada a professores), complementada por alguns resultados qualitativos obtidos com a aplicação de instrumento virtual previamente construído para levantar informações sobre o tema. (OSTERMANN, 2005, p. 9).

\section{Quanto aos conteúdos abordados}

O outro aspecto de análise consistiu em verificar os conteúdos abordados nas atividades. Um fator observado que cabe destacar foi a quantidade de trabalhos que abordaram 
conteúdos relacionados à Física Moderna, superando inclusive aqueles que abordaram os conteúdos de Cinemática.

As atividades relacionadas com Cinemática apresentaram uma relevância menor, porém ainda com uma considerável quantização. A figura 01 apresenta os resultados encontrados neste item:

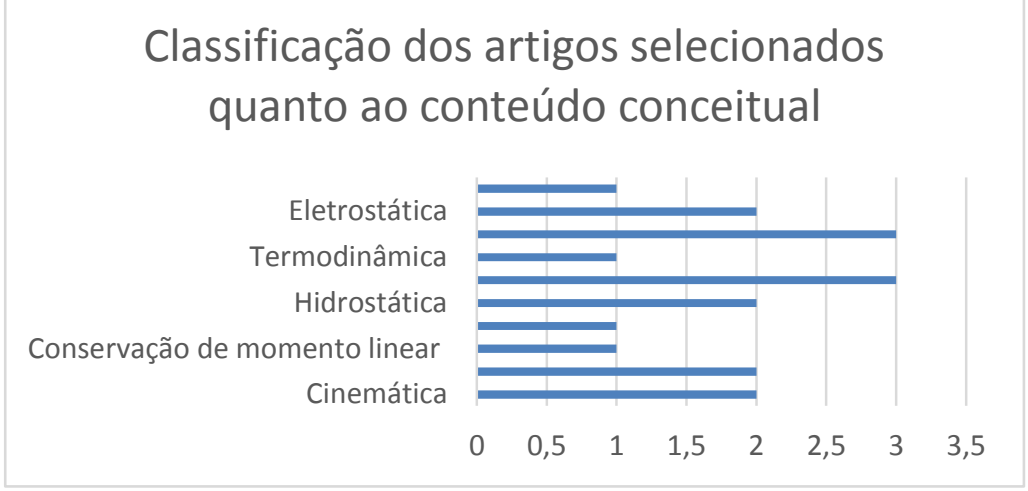

Figura 1 - Conteúdos conceituais das publicações do CBEF

\section{Revista Brasileira de Ensino de Física}

Foram analisados 789 artigos, publicados entre janeiro de 2000 e dezembro de 2011. Desta análise, resultaram 133 artigos que utilizavam o computador como ferramenta didática. Após isso, a segunda etapa de seleção consistiu em separar os artigos que estavam voltados à sala de aula (foco deste trabalho). Com este filtro, 48 artigos foram descartados, restando, então, 85 trabalhos. A Tabela 2 apresenta o número de artigos publicados em cada do ano, além da porcentagem de artigos selecionados em relação ao número total.

Tabela 2 - Número de artigos publicados em cada ano na RBEF

\begin{tabular}{c|c|c|c}
\hline Ano & N de artigos & $\begin{array}{c}\text { Artigos } \\
\text { Selecionados }\end{array}$ & Porcentagem \\
\hline 2000 & 71 & 9 & 12,6 \\
\hline 2001 & 57 & 7 & 12,2 \\
\hline 2002 & 59 & 21 & 35,6 \\
\hline 2003 & 47 & 5 & 10,6 \\
\hline 2004 & 54 & 15 & 27,7 \\
\hline 2005 & 76 & 10 & 13,1 \\
\hline 2006 & 65 & 15 & 23,1 \\
\hline 2007 & 79 & 10 & 12,6 \\
\hline 2008 & 63 & 9 & 14,2 \\
\hline 2009 & 63 & 9 & 14,2 \\
\hline 2010 & 64 & 5 & 7.8 \\
\hline & & & \\
\hline
\end{tabular}




\begin{tabular}{c|c|c|c}
\hline 2011 & 91 & 18 & 19,7 \\
\hline Total & 789 & 133 & 16,8 \\
\hline
\end{tabular}

Apesar de existir alguns anos com um número razoável de publicações relacionadas ao tema - devido à existência de publicações especiais ${ }^{6}$ que tratavam unicamente do uso do computador como ferramenta didática, como em 2002 e $2004-$ visualiza-se certa linearidade no número de publicações e o valor de $16,8 \%$ corresponde a uma taxa significativa dos artigos analisados. Abaixo, destacam-se as classificações realizadas para este periódico.

\section{Voltados à sala de aula}

Através da (ATD) (MORAES; GALIAZZI, 2006), emergiram quatro categorias:

- Simulações Computacionais: a mais recorrente manifestação sobre o uso de computadores em sala de aula deu-se por meio de simulações computacionais. Isto representou $47 \%$ dos trabalhos desenvolvidos, o que, sem dúvida, é um número considerável quando comparado à totalidade dos artigos selecionados.

Assim como na análise realizada no periódico anterior, aqui também foi possível evidenciar que as atividades de simulações computacionais estão presentes no contexto de sala de aula, tanto no nível médio quanto no nível superior. O texto abaixo caracteriza a categoria.

Neste trabalho é apresentada a ferramenta de software Easy Java Simulations (EJS). Além de citar suas principais características e potencialidades na produção de simulações-Applets dirigidas ao ensino de Física, desenvolvemse duas aplicações de modelagem em atividades de ensino: um sistema massa-mola e a solução numérica da Equação Schroedinger independente do tempo. (FILGUEIRA, 2005, p.613).

- Atividade Experimental: Aproximadamente 35\% dos textos baseavam-se em atividades experimentais. Nestas atividades, o computador foi fundamental nos processos de coleta de dados e análise/construção de gráficos. O texto abaixo traz algumas evidências relacionadas a esta categoria.

Com a finalidade de testarmos nosso sistema experimental, realizamos algumas medidas envolvendo um circuito básico RC serial. Investigamos a forma de onda observada nos circuitos tipo passa-baixa e passa-alta nas configurações de integrador e diferenciador, respectivamente. (MAGNO et al, 2004, p.117).

Analisando esta citação, a utilização do computador como parte do aparato experimental da atividade é nítida. Observa-se que sua utilização também pode estar vinculada à análise e reprodução de gráficos.

- Aprendizagem: esta categoria representa uma parcela de aproximadamente $8 \%$ dos textos que abordam aspectos relacionados a teorias de aprendizagem associadas ao uso do computador em sala de aula. O texto abaixo, extraído de um dos artigos selecionados, representa características da categoria.

\footnotetext{
${ }^{6}$ São publicações que tratam unicamente de algum tema, como por exemplo, naqueles anos, o uso do computador em sala de aula.
} 
Fazemos uma breve análise da hierarquia de objetivos educacionais no domínio cognitivo seguindo a taxonomia sugerida por Bloom. Por outro lado, usamos a computação algébrica para construir as figuras de Lissajous e as comparamos com as já existentes na literatura. Classificamos a comparação das figuras obtidas com as já existentes como um processo ao terceiro nível da taxonomia de Bloom, o de aplicação. (ANDRADE; CAMPOS, 2005, p.587).

- Vídeos: esta categoria emergiu a partir das atividades que utilizavam o computador como ferramenta de construção ou visualização de vídeos. Esta utilização esteve presente em aproximadamente $10 \%$ dos artigos selecionados. $O$ trecho abaixo representa a categoria: "Através de uma filmadora digital e do software de domínio público VirtualDub consegue-se registrar espacial e temporalmente a evolução dinâmica de um sistema muito rápido, como por exemplo, a queda livre" (SISMANOGLU et al ,2009, p.1501).

A análise realizada possibilitou também verificar que, na maior parte das atividades selecionadas nesta categoria, o texto esteve atrelado ao conteúdo de cinemática. Neste contexto, observa-se a utilização de gravações de diferentes tipos de movimento para análise de gráficos ligados ao Movimento Retilíneo Uniformemente Variado.

\section{Quanto aos conteúdos abordados}

A Figura 2 apresenta uma perspectiva da divisão dos conteúdos das atividades em função do número de publicações. Cabe ressaltar que 66 artigos estavam estruturados a partir de algum conteúdo ${ }^{7}$.

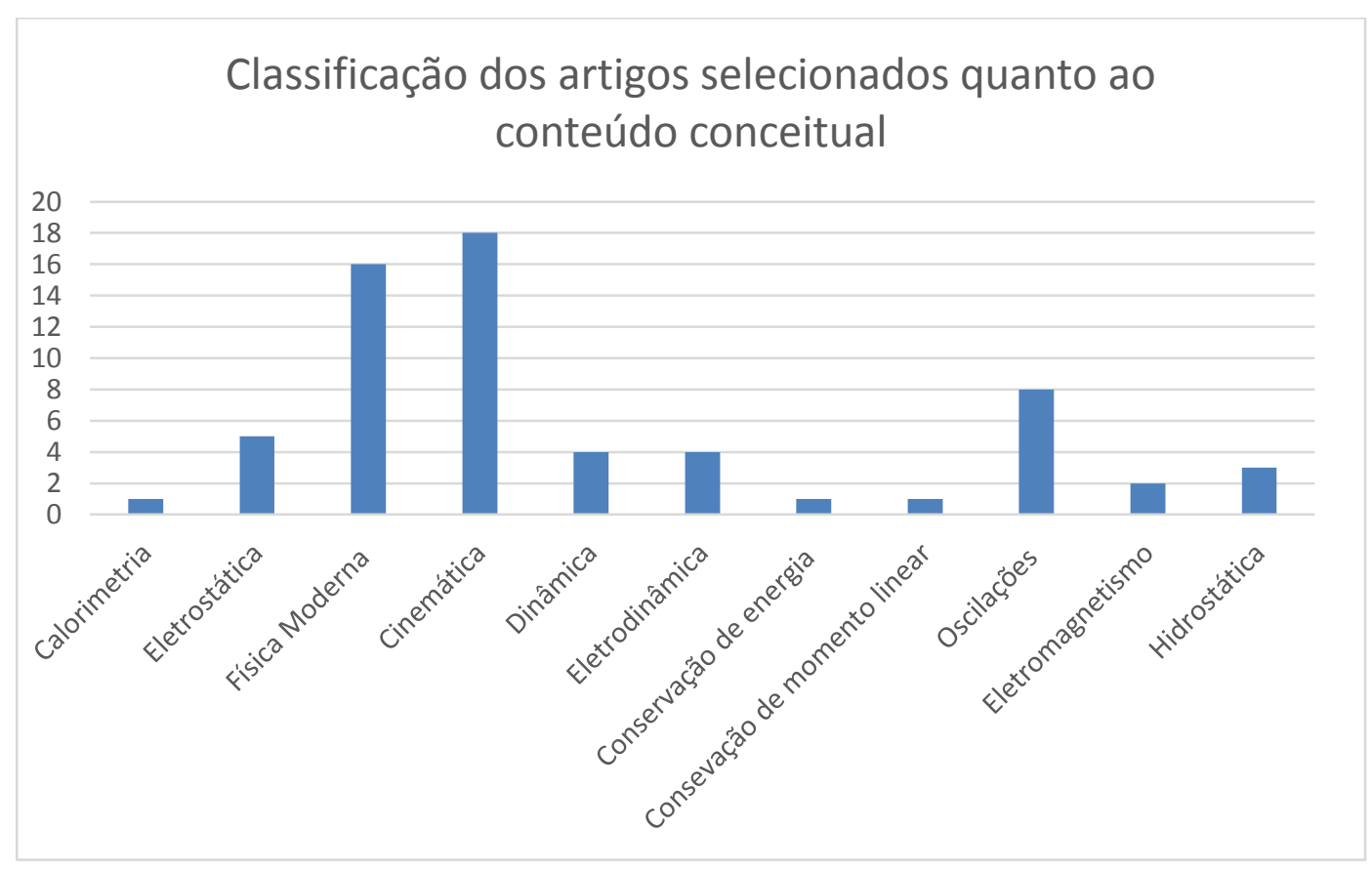

Figura 2 - Conteúdos conceituais das publicações do RBEF

\footnotetext{
${ }^{7}$ Aborda-se aqui apenas os conteúdos conceituais ligados ao conteúdo programático da Física. Alguns artigos que tratavam de conteúdos relacionados a Matemática, como cálculo diferencial e integral, não aparecem na figura 2 .
} 
A leitura destes dados mostra que o conteúdo Cinemática está presente em 18 artigos, o que corresponde aproximadamente a $27 \%$ das publicações. Porém, outros dois fatores de interesse podem ser discutidos a partir do gráfico: o primeiro é a grande fatia, quase em igualdade com a da Cinemática, das publicações relacionadas a Física Moderna; o segundo, uma considerável parcela dos trabalhos ligados diretamente ao conteúdo de oscilações. Na proxima seção será dado enfase a estas considerações.

\section{CONSIDERAÇÕES FINAIS}

Pela pesquisa realizada, no que confere ao uso do computador como atividade didática, esta prática mostra-se recorrente - segundo os periódicos analisados -, sendo aplicadas de cinco formas diferentes: simulação computacional, atividades experimentais, aprendizagem, vídeos e formação de professores.

A categoria simulação computacional engloba o uso de diferentes objetos de aprendizagem, simulações computacionais, modelagens computacionais e outros softwares empregados em sala de aula. $\mathrm{Na}$ análise realizada, verificou-se que esta prática está presente em diferentes níveis de ensino, o que comprova o questionamento inicial, no qual se pergunta se atividades deste caráter estavam sendo empregadas nas práticas didáticas de sala de aula.

Com relação à categoria atividade experimental, o computador tem sido utilizado como ferramenta na coleta de dados, e análise e interpretação de gráficos. Mas esta prática, quantitativamente, já aparece em minoria quando comparada a de simulação computacional.

As outras três categorias restantes (aprendizagem, vídeos e formação de professores - estas duas últimas em revistas diferentes) representadas em menor escala discutiram aspectos relacionados à aprendizagem dos alunos em atividades computacionais, construção e análise de vídeos e, por fim, atividades de formação de professores.

Quanto aos conteúdos, embora houvesse uma diferença nos resultados dos dois periódicos, observou-se uma predominância com a Cinemática. Porém, há outros fatores que necessitam uma discussão mais aprofundada, como o número considerável de atividades relacionadas com o tema Física Moderna. Para uma primeira justificativa deste resultado, acredita-se que as simulações computacionais sobre este tema são de maior acesso do que os experimentos reais, os quais são em grande parte caros e de difícil acesso para a maioria das escolas/universidades.

Este aspecto é evidenciado por Fiolhais (2003), que afirma que as simulações computacionais são excelentes alternativas para trabalhar atividades experimentais, quando de alguma maneira (econômica, de infraestrutura ou social) não se apresenta um laboratório de Ciências Naturais adequado para práticas deste tipo. Isso, vem ao encontro do atual quadro da pesquisa em simulações computacionais, que, indica essa vertente como grande potencial para sua utilização em sala de aula.

\section{REFERÊNCIAS}

ANDRADE, D.; CAMPOS, M. Análise do processo cognitivo na construção das figuras de Lissajous. Revista Brasileira de Ensino de Física. v.27, n.4, p.587-591, 2005. 
ARAUJO, I.S.; VEIT, E.A. Uma revisão da literatura sobre estudos relativos a tecnologias computacionais no ensino de Física. Revista Brasileira de Educação em Ciências. v.4, n.3, p.5-18, 2004.

BRASIL. Ministério da Educação. Secretaria da Educação Média e Tecnológica. Parâmetros Curriculares Nacionais+ $(\mathrm{PCN}+)$ - Ciências da Natureza e suas Tecnologias. Brasília: MEC, 2002.

BRASIL. Instituto Nacional de Estudos e Pesquisas Educacionais Anísio Teixeira. Censo Escolar 2010 - Resumo Técnico. Brasília, 2010. Disponível em: <http://portal.inep.gov.br/resumos-tecnicos >. Acesso em: 6 mar. 2015.

FILGUEIRA, J.S. Easy Java simulations - Modelagem computacional para o ensino de Física. Revista Brasileira de Ensino de Física. v.27, n.4, p.613-618, 2005.

FIOLHAIS, C.; TRINDADE, J. Física no Computador: O Computador como uma Ferramenta no Ensino e na Aprendizagem das Ciências Físicas. Revista Brasileira de Ensino de Física, v. 25, n.3, p.259-272, 2003.

HEINECK, R.; VALIATI, E. R. A.; ROSA, C. T. W. Software educativo no ensino de Física: análise quantitativa e qualitativa. Rev. Iberoamericana de Educación. N 42/6, OEI, maio de 2007.

MACEDO, J.A.; DICKMAN, A.G.; ANDRADE, I.S.F.; Simulações computacionais como ferramentas para o ensino de conceitos básicos de eletricidade. Caderno Brasileiro de Ensino de Física. v.29, n. Especial 1, p.562-613, 2012.

MAGNO, W.C.; ARAUJO, A. E. P.; LUCENA, M. A.; MONTARROYOS, E. Realizando experimentos didáticos com o sistema de som de um PC. Revista Brasileira de Ensino de Física. v.26, n.1, p.117-123, 2004.

MORAES, R.; GALIAZZI, M. D. Análise textual discursiva: processo reconstrutivo de múltiplas faces. Ciência \& Educação. v. 12, n. 1, p. 117-128, 2006.

OSTERMANN, F. Conceitos de Física Quântica na formação de professores: relatos de uma experiência didática centrada no uso de experimentos virtuais. Caderno Brasileiro de Ensino de Física. v.22, n.1, p.9-35, 2005.

SANTOS, G.; OTERO, M.R.; FANARO, M.L.G. Cómo usar software de simulación em clases de Física? Caderno Brasileiro de Ensino de Física. v.17, n.1, p.50-66, 2000.

SILVA, W.P.; CLEIDE, M. D. P. S; DIOGO, D. P. S.; CLEITON, D. P. S. Um software para experimentos sobre batimentos de ondas sonoras. Caderno Brasileiro de Ensino de Física. v.21, n.1, p.103-110, 2004.

SISMANOGLU, B.N.; GERMANO, J. S. E.; AMORIN, J.; CAETANO, R. A utilização da filmadora para o estudo do movimento dos corpos. Revista Brasileira de Ensino de Física. v.31, n.1, p.1501, 2009. 